Article

\title{
Extractants Based on Coordinating Liquid Polar Solvents for Removal of Sulfur Compounds from Diesel Fuels
}

\author{
Natalia Stanislavovna Kobotaeva ${ }^{1,2}$, Tatiana Sergeevna Skorokhodova ${ }^{2}$, \\ Oleg Semenovich Andrienko ${ }^{1,3}$ (10), Elena Ivanovna Marakina ${ }^{1}$ \\ and Victor Ivanovich Sachkov $1, *$ (i) \\ 1 National Research Tomsk State University, Lenin Avenue 36, 634050 Tomsk, Russia; nat@ipc.tsc.ru (N.S.K.); \\ aos@iao.ru (O.S.A.); vioes@mail.ru (E.I.M.) \\ 2 Institute of Petroleum Chemistry SB RAS, 4, Akademichesky Avenue, 634055 Tomsk, Russia; see@ipc.tsc.ru \\ 3 V.E. Zuev Institute of Atmospheric Optics SB RAS, 1, Academician Zuev Square, 634055 Tomsk, Russia \\ * Correspondence: vicsachkov@gmail.com; Tel.: +7-913-889-1729
}

Received: 29 June 2018; Accepted: 25 July 2018; Published: 30 July 2018

check for updates

\begin{abstract}
To remove sulfur-containing compounds (SCC) from the diesel fraction $200-360{ }^{\circ} \mathrm{C}$ extraction systems have been created based on coordinating organic solvents-dimethylformamide and dimethylsulfoxide, metal chlorides $\left(\mathrm{CoCl}_{2}, \mathrm{CuCl}_{2}, \mathrm{CdCl}_{2}, \mathrm{MnCl}_{2}\right.$ and $\left.\mathrm{CrCl}_{3}\right)$, and metal trifluoroacetates $\left(\mathrm{Co}(\mathrm{TFA})_{2}, \mathrm{Cu}(\mathrm{TFA})_{2}\right.$ and $\left.\mathrm{Mn}(\mathrm{TFA})_{2}\right)$. Using PMR spectroscopy the coordination of metal chloride and metal trifluoroacetate on the oxygen atom in the carbonyl group of DMF was shown to redistribute electron density in the solvent molecule and to enhance properties of the acceptor center localized on the nitrogen atom. The removal of sulfur-containing compounds from the diesel fraction proceeded under mild conditions-at the temperature of $25^{\circ} \mathrm{C}$ and atmospheric pressure. The degree of SCC removal from the diesel fraction in 30 minutes extraction was more than $90 \%$. The interaction of organic solvents with metal salts and sulfur-containing compounds of the diesel fraction was considered within the framework of the concept of "hard and soft acids and bases" (HSAB). The most complete SCC extraction was carried out with DMF-Mn(TFA) $)_{2}, \mathrm{MnCl}_{2}$ and $\mathrm{CrCl}_{3}$ systems, that was probably connected with the implementation of the 'hard base-hard acid' system.
\end{abstract}

Keywords: extractants; sulfur compounds; diesel fraction; coordinating solvents; chlorides; metal trifluoroacetates; dimethylformamide

\section{Introduction}

Nowadays, the emphasis in the oil industry shifts to the extraction and processing of heavy, high-viscosity, high pour point sulfurous oil and oil residues. Most of the world's produced oil is sulfurous and high sulfur oil. Their total sulfur content varies between very wide limits from 0.5 to $10 \%$ by weight [1]. Sulfur contained in oils is mostly represented by its organic compounds. To date, more than 250 compounds have been identified [1-3]. The efforts of researchers to extract sulfur-containing compounds (SCC) and establish their structure are focused on middle distillate fractions, representing the main raw material base for practical use. Organosulfur compounds of most middle distillate fractions of sulphur and high sulfur oils are mainly presented by sulfides and thiophene homologues mixed in various ratios [1].

To date, special attention has been paid to technologies for processing of such high-sulfur oils $[4,5]$. The process of hydrotreatment over solid-phase catalysts is extensively applied to remove sulfur impurities from hydrocarbons. Its main disadvantages are the use of catalysts, large volumes of hydrogen, and high pressures. The process is economically irrational due to high cost for small and medium-sized plants. This is one of the reasons for development of alternative approaches to the hydrocarbon feed purification. 
Currently, the process of extraction desulfurization aimed to reduce the sulfur content of diesel fuels is actively developing [6,7]. In addition to the fact that the extraction is carried out under mild conditions, the extraction processes cause no changes in the chemical structure of diesel fuel components and allow removing not only sulfur-containing compounds, but also aromatic hydrocarbons. An extraction process is based on the higher solubility of sulfur-containing components and aromatic hydrocarbons compared to that of non-aromatic hydrocarbons in well-suited polar solvents. The effectiveness of desulfurization depends on the correct solvent selection, the chemical activity of the components being removed, and other factors including environmental and toxicological aspects. The most commonly used solvents for the extraction of desulfurization of diesel fuel are $\mathrm{N}, \mathrm{N}$-dimethylformamide (DMF), dimethylsulfoxide (DMSO), acetonitrile [6,7], $\mathrm{N}$-methy-2-lpyrrolidone [8], and polyethylene glycol [9].

The extraction of organic sulfides and sulfoxides from high-sulfur diesel distillates, in particular, a diesel distillate of a mixture of oils from the Gazlinskoye oil and gas field and Fergana oil and gas region (boiling point: $140-360{ }^{\circ} \mathrm{C}$ ) using methanol, acetonitrile, dimethylformamide, and dimethylsulfoxide as extractants, and also mixtures of these solvents with 5-20\% water is reported in [7]. In addition to these solvents, solutions of zinc bromide in methanol, butanol, and sulfuric acid (20-94\%) were used.

An investigation of a number of aprotic and proton-donating polar solvents and extraction systems, including a nonpolar solvent (hexane) used as extractants for the removal of sulfur-containing compounds from the diesel fraction of high-sulfur oil from South Uzbekistan has shown that effective desulfurization of the fraction is achieved using the phenol-water-hexane extraction system [10].

It is possible to reduce the sulfur content in oil objects by using of modified organic solvents during the extraction desulfurization. For this purpose, metal salts are introduced into coordinating organic solvents. It was found out that an introduction of electron-withdrawing compounds represented by metal chlorides $(\mathrm{Cd}, \mathrm{Cu}, \mathrm{Ni}, \mathrm{Co}, \mathrm{Mn}, \mathrm{Cr}, \mathrm{Zn}$, and $\mathrm{Li}$ ) into coordinating organic DMF, DMSO, and propylene carbonate (PC) solvents, and the use of these systems in the course of desulfurization results in a decrease in content of sulfur compounds in diesel fuels $[8,9]$.

Thus, an analysis of the literature data shows that organic solvents may be well suited for the extraction of sulfur-containing compounds from the diesel fraction. Coordinating polar solvents, which prove to be electron-donating group, are of a particular interest. In addition, their ability to extract sulfur compounds can be enhanced by adding of electron-accepting additives.

This work deals with the removing sulfur from a diesel fuel by extraction with selective solvents (DMF, DMSO) coordinating with electron-accepting solvents represented by metal salts (copper, cobalt, manganese, chromium, and cadmium chlorides) and even more strong electron-accepting group - metal trifluoroacetates (copper, cobalt, and manganese).

\section{Materials and Methods}

\subsection{Raw Materials and Reagents}

The investigation was made of the diesel fraction with a total sulfur content of $0.22 \%$ boiling in the range of temperature from 200 to $360^{\circ} \mathrm{C}$. The content of sulfides (thiamonocyclanes, thiabicyclanes, dialkyl sulfides, cycloalkyl sulfides, and alkylarylsulfides) was $68 \%$, while that of thiophenes was $23 \%$ and that of hydrocarbons $9 \%$.

According to Specifications GOST 20289-74 and Specifications GOST TU6-09-3818-89 dimethylformamide (DMF) and dimethylsulfoxide (DMSO) were used as solvents.

Metal salts used were cadmium chloride hemi(pentahydrate), $\mathrm{CdCl}_{2} \cdot 2^{1} /{ }_{2} \mathrm{H}_{2} \mathrm{O}$, analytical grade, GOST (Russian State Standard) 4330-76; cobalt(II) chloride hexahydrate, $\mathrm{CoCl}_{2} \cdot 6 \mathrm{H}_{2} \mathrm{O}$, analytical grade, GOST 4525-77; manganese(II) chloride dehydrate, $\mathrm{MnCl}_{2} \cdot 4 \mathrm{H}_{2} \mathrm{O}$, analytical grade, GOST Russian State Standard 612-75; copper(II) chloride dehydrate, $\mathrm{CuCl}_{2} \cdot 2 \mathrm{H}_{2} \mathrm{O}$, analytical grade, GOST 4167-74; chromium(III) chloride hexahydrate, $\mathrm{CrCl}_{3} \cdot 6 \mathrm{H}_{2} \mathrm{O}$, analytical grade, GOST 4473-78. 
Metal trifluoroacetates, i.e., $\mathrm{Co}(\mathrm{TFA})_{2}$ cobalt trifluoroacetate, $\mathrm{Mn}(\mathrm{TFA})_{2}$ manganese trifluoroacetate, and $\mathrm{Cu}(\mathrm{TFA})_{2}$ copper trifluoroacetate were prepared by the methods of obtaining metal acetates described in [11-14].

\subsection{Preparation Method}

Procedure for preparing extraction systems (ES). A $100 \mathrm{~cm}^{3}$ flat-bottom conical flask equipped with a Liebig condenser and containing $10 \mathrm{~cm}^{3}$ of DMF (DMSO) was placed on a IKA RET Basic magnetic stirrer (Staufen im Breisgau, Germany). The salt of corresponding metal $\left(0.2 \mathrm{~g}\right.$ of $\mathrm{CdCl}_{2} \cdot 2 \cdot 5 \mathrm{H}_{2} \mathrm{O}$, $0.138 \mathrm{~g}$ of $\mathrm{MnCl}_{2} \cdot 2 \mathrm{H}_{2} \mathrm{O}, 0.293 \mathrm{~g}$ of $\mathrm{CrCl}_{3} \cdot 6 \mathrm{H}_{2} \mathrm{O}, 0.262 \mathrm{~g}$ of $\mathrm{CoCl}_{2} \cdot 6 \mathrm{H}_{2} \mathrm{O}, 0.29 \mathrm{~g}$ of $\mathrm{Cu}(\mathrm{TFA})_{2}$, Co(TFA) $)_{2}$, and $\mathrm{Mn}(\mathrm{TFA})_{2}$ ) were added until the salt was completely dissolved.

\subsection{Methods of Investigation}

Intermolecular interactions were investigated by NMR spectroscopy using a Bruker AVANCE III $400 \mathrm{MHz}$ NMR spectrometer (Bruker BioSpin GmbH, Rheinstetten, Germany).

The total content of sulfur (Stot) in samples was determined using a 'SpectroScan S' (GOST R 51947-2002) X-ray fluorescence energy dispersive analyzer (MILLAB Co., Moscow, Russia) of sulfur in petroleum and petroleum products. The range of measurement of mass fraction of sulfur was from $0.002 \%$ to $5 \%$.

\section{Results and Discussion}

\subsection{Isolation of SCC by DMSO-CdCl $, \mathrm{CoCl}_{2}, \mathrm{CuCl}_{2}, \mathrm{MnCl}_{2}, \mathrm{CrCl}_{3}, \mathrm{Co}(\mathrm{TFA})_{2}, \mathrm{Mn}(\mathrm{TPA})_{2}, \mathrm{Cu}(\mathrm{TFA})_{2}$ Extraction Systems}

The organic solvent as the main component of the extraction system (ES) must satisfy following requirements: to be immiscible with the hydrocarbon phase and dissolve metal chlorides and metal trifluoroacetates. Dissolution of inorganic salts in organic solvents is due to the effects of solvation and coordination. The effect of solvation is provided by $\eta$-donating solvents, whose heteroatoms have a lone electron pair. These solvents, DMF and DMSO, were used in our experiment.

Data on the extraction of the SCC fraction boiling in the temperature range of $200-350{ }^{\circ} \mathrm{C}$ with solutions of metal chlorides in DMF are given in Table 1.

Table 1. Results of extraction of sulfur compounds from the diesel oil fraction $\left(200-350{ }^{\circ} \mathrm{C}\right)$ with solutions of chlorides and TFA metals in DMF. The total sulfur content (St) in the initial sample is $0.22 \%$, $\mathrm{n}_{\mathrm{d}}{ }^{20}(\mathrm{DT})=1.4655$. $\mathrm{S}_{\text {tot }}$ content in the initial sample after treatment with DMF is $0.12 \%$. The extraction time is $30 \mathrm{~min}$. The temperature is $25^{\circ} \mathrm{C}$.

\begin{tabular}{|c|c|c|c|c|c|c|}
\hline $\begin{array}{c}\text { Metal } \\
\text { Salts }\end{array}$ & $\begin{array}{l}\text { Concentration } \\
\text { of Metal Salt in } \\
\text { DMF, mol/dm }\end{array}$ & $S(1)_{t}, \%$ & $\begin{array}{l}\quad \text { Degree of } \\
\quad \text { Extraction of } \\
\text { Sulfur Compounds, } \\
\% \text { (First Extraction) }\end{array}$ & $S(2)_{t}, \%$ & $\begin{array}{c}\text { Degree of Extraction } \\
\text { of Sulfur } \\
\text { Compounds, \% } \\
\text { (Second Extraction) }\end{array}$ & $\begin{array}{l}\text { Refraction Index } \\
\text { after Removal of } \\
\text { SCC with } \\
\text { Extraction Systems, } \\
n_{\mathrm{d}}{ }^{20}\end{array}$ \\
\hline $\mathrm{CdCl}_{2}$ & 0.12 & 0.110 & 38.8 & 0.06 & 66.5 & 1.4571 \\
\hline $\mathrm{CoCl}_{2}$ & 0.50 & 0.055 & 69.4 & 0.05 & 72.2 & 1.4571 \\
\hline $\mathrm{CuCl}_{2}$ & 1.76 & 0.060 & 66.5 & 0.05 & 72.2 & 1.4569 \\
\hline $\mathrm{MnCl}_{2}$ & 2.50 & 0.050 & 72.2 & traces & - & 1.4569 \\
\hline $\mathrm{CrCl}_{3}$ & 2.75 & 0.050 & 72.2 & traces & - & 1.4569 \\
\hline $\mathrm{Co}(\mathrm{TFA})$ & 0.11 & 0.035 & 80.5 & traces & - & 1.4566 \\
\hline $\mathrm{Mn}(\mathrm{TFA})_{2}$ & 0.11 & 0.030 & 83.3 & traces & - & 1.4565 \\
\hline $\mathrm{Cu}(\mathrm{TFA})_{2}$ & 0.11 & 0.04 & 77.7 & traces & - & 1.4568 \\
\hline
\end{tabular}

According to the data presented in Table 1, the treatment of diesel fuel with DMF allows reducing the total sulfur content to $0.12 \%$. However, SCC removal using the 'DMF-chlorides, metal trifluoroacetates' extraction systems is more efficient. We can make some assumptions about the dependence of the rate of SCC extraction with extraction systems (ES) on the type of metal cations. According to the results presented in Table 1, a general trend is observed: After introduction of metal 
salts into DMF its extraction capacity relative to sulfur-containing compounds of diesel fuels increases as compared to DMF without metal salts. Only trace amounts of sulfur-containing compounds remain in diesel fuels after two extractions.

A comparison of the results obtained with those of other investigations has shown that the value of degree of removal of sulfur-containing compounds approaches or even exceeds the known values for the removal of SCC obtained with the use of other extraction systems. The data on the extraction of SCC from diesel fuels using one of the most effective extractants, $N$-methyl-2-pyrrolidone, are reported in [11].

The efficiency of ES in the case of use of chlorides and metal trifluoroacetates can be explained on basis of Pearson hard-soft acid-base theory (HSAB) [15]. According to this concept, the interaction of a soft (hard) acid with a soft (hard) base proceeds more quickly or results in a more favorable equilibrium position.

In our case, among the used metal chlorides, cadmium chloride can be identified as a mild Lewis acid, while cobalt, nickel and copper chlorides as Lewis intermediate acids. Manganese and chromium chloride are identified as hard acids. If we consider the process of dissolving metal chlorides in an organic solvent as an acid-base Lewis interaction, then manganese chloride and chromium chloride react with DMF as a hard base and a hard acid and, according to the HSAB concept, form the most stable compounds. According to the data in Table 1, the highest yield in sulfur is given by ES, when the interaction of a hard acid-hard base $\left(\mathrm{MnCl}_{2}\right.$ or $\mathrm{CrCl}_{3}$-DMF) occurs. To the contrary, the lower yield for sulfur is given by ES when the hard base-mild acid ( $\left.\mathrm{CdCl}_{2}-\mathrm{DMF}\right)$ interaction is observed.

\subsection{Study of Intermolecular Interactions in the 'DMF-Metal Salt-Model Compound' System by the Method of PMR Spectroscopy}

To study intermolecular interactions in the DMF-metal salt system, the PMR method was chosen, whose high sensitivity allows us to register weak intermolecular interactions. The PMR method was used to study interactions in the organic solvent-metal chloride-model compound system. Dihexylsulfide and dibenzothiophene were used as model compounds.

Figure 1 shows a graphical representation of PMR spectra of I-DMF and II-DMF with $\mathrm{CoCl}_{2}$. According to the spectra, when the cobalt chloride is added to the DMF solution, the proton signals are shifted to the weak-field region. This fact indicates that in the presence of metal chloride a solvent molecule behaves like an electron donor [12].
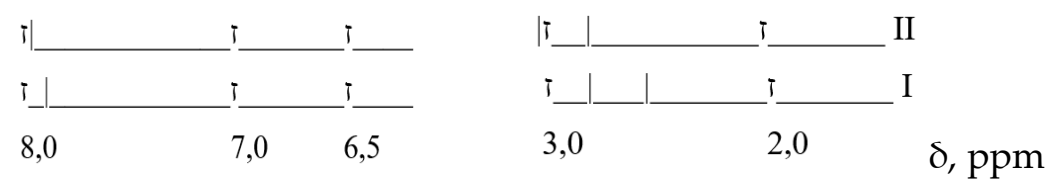

Figure 1. Graphic presentation of PMR spectra of dimethylformamide and the complex 'Dimethylformamide-cobalt chloride'. I-DMF; II-DMF with $\mathrm{CoCl}_{2}$.

It can be assumed that the metal cation is coordinated to the carbonyl group of solvent through its oxygen atom, which results in an enhancement of the properties of the acceptor center localized on the nitrogen atom and leads to a more complete extraction of sulfur compounds from diesel fuels using ES. Table 2 shows the PMR spectra of solutions of model compounds in DMF.

Table 2. Data of the PMR spectra of model compounds in carbon tetrachloride $\left(0.2 \mathrm{~mol} / \mathrm{dm}^{3}\right)$.

\begin{tabular}{ccccccccc}
\hline \multirow{3}{*}{ Compounds, Molecular Ratio } & \multicolumn{8}{c}{ Chemical Shifts, ppm } \\
\cline { 2 - 9 } & \multicolumn{7}{c}{ DMF } & \multicolumn{7}{c}{ Aliphatic Protons and Protons in Aromatic Rings } \\
\cline { 2 - 8 } & $\mathbf{C H}_{3}{ }^{\mathbf{a}}$ & $\mathbf{C H}_{3}{ }^{\mathbf{b}}$ & $\mathbf{H}^{\mathbf{c}}$ & $\mathbf{C H}_{2} \alpha$ & $\mathbf{C H}_{2} \boldsymbol{\beta}$ & $\mathbf{C H}_{3} \gamma$ & Ring \\
\hline N,N-dimethylformamide & 2.83 & 2.95 & 7.83 & - & - & - & - \\
\hline Dihexylsulfide (DHS) & - & - & - & 2.42 & $1.76-1.1(8 \mathrm{H})$ & 0.92 & - \\
\hline DHS:DMF $=1: 1$ & 2.76 & 2.91 & 7.91 & 2.46 & $1.76-1.1$ & 0.89 & - \\
\hline
\end{tabular}


Table 2. Cont.

\begin{tabular}{|c|c|c|c|c|c|c|c|}
\hline \multirow{3}{*}{ Compounds, Molecular Ratio } & \multicolumn{7}{|c|}{ Chemical Shifts, ppm } \\
\hline & \multicolumn{3}{|c|}{ DMF } & \multicolumn{4}{|c|}{ Aliphatic Protons and Protons in Aromatic Rings } \\
\hline & $\mathrm{CH}_{3}{ }^{\mathrm{a}}$ & $\mathrm{CH}_{3}{ }^{\mathrm{b}}$ & $\mathbf{H}^{\mathrm{c}}$ & $\mathrm{CH}_{2} \alpha$ & $\mathrm{CH}_{2} \beta$ & $\mathrm{CH}_{3} \gamma$ & Ring \\
\hline Dibenzothiophene (DBT) & & & & & & & $\begin{array}{l}8.14-7.98 \\
7.90-7.60 \\
7.50-7.20\end{array}$ \\
\hline DBT-DMF & 2.76 & 2.86 & 7.98 & & & & $\begin{array}{l}8.40-8.14 \\
8.04-7.80 \\
7.55-7.80\end{array}$ \\
\hline
\end{tabular}

In all cases, the signals of all protons of DMF are shifted to a strong field, while those of protons of model compounds are shifted to a weak field, i.e., a DMF molecule behaves like an acceptor, while a molecule of the model compound acts as an electron donor. The highest absolute values of proton shifts of DMF methyl groups are observed for dibenzothiophene, while the lowest ones for dipropylsulfide. This suggests a weak interaction between DMF and sulphide and a stronger one with aromatic compounds. In the practice of DMF extracting this should be manifested in the preferred extraction of aromatic compounds.

If it is assumed that the interaction of metal salts, as electron-accepting compounds, with DMF is due to the coordination of the metal cation through the oxygen atom of the carbonyl group of negatively charged solvent. The result of this interaction is the redistribution of the electron density in the dimethylformamide molecule and the enhancement of the properties of the acceptor center localized on the nitrogen atom. Hence, sulfur compounds of a diesel fuel represented mainly by sulfides and thiophene derivatives having an excess electron density on the sulfur atom will easier interact with the DMF-metal salt systems than with DMF.

Table 1 also shows the refractive indices of the diesel fraction after extraction of SCC with extraction systems. The refractive index of the desulfurized samples of diesel fraction is reduced, which indirectly indicates a decrease in the content of aromatic hydrocarbons in the desulfurized sample. To confirm this assumption, the ${ }^{13} \mathrm{C}$ NMR and PMR spectra were registered for the initial and desulfurized diesel fraction (Figures 2 and 3).

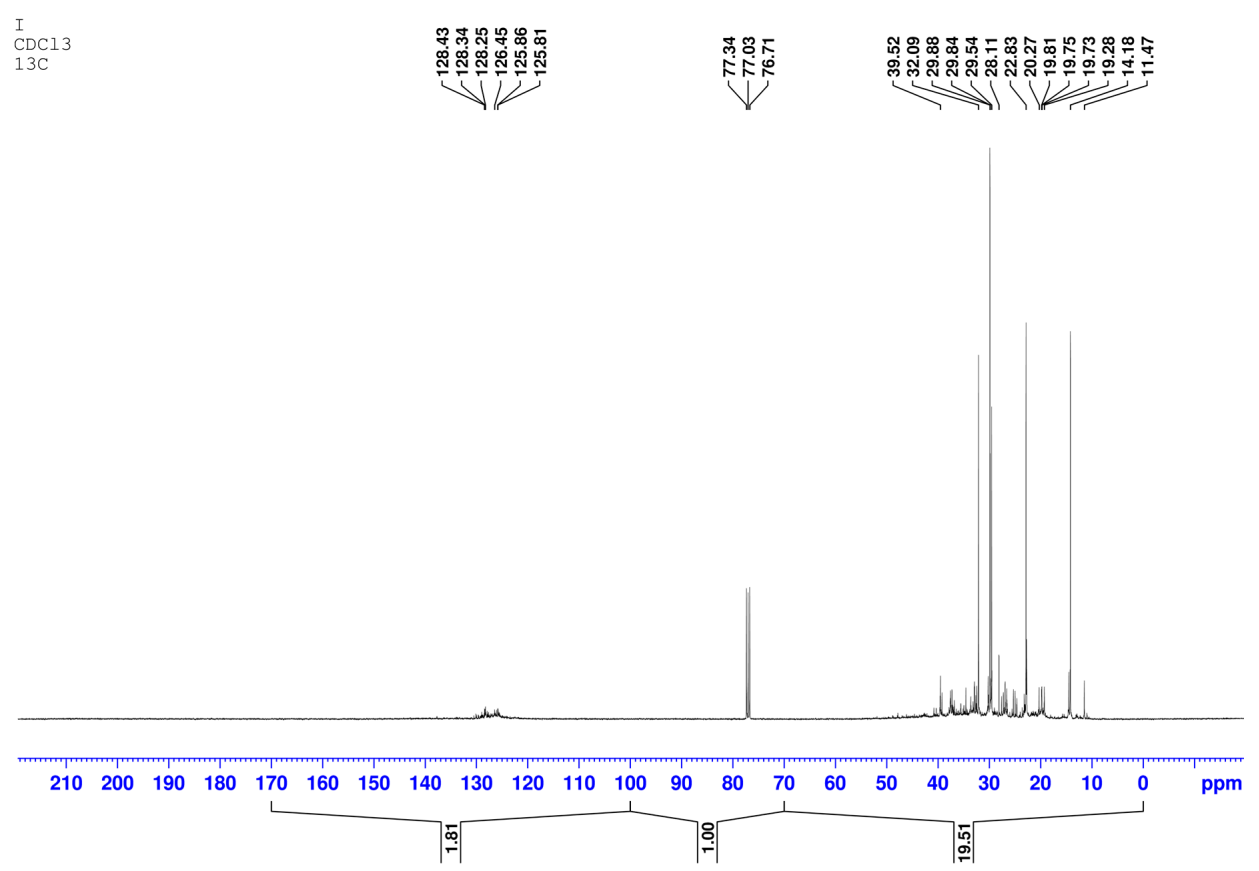

Figure $2 .{ }^{13} \mathrm{C}$ NMR spectra of the diesel fraction boiling at $200-350{ }^{\circ} \mathrm{C}$. 


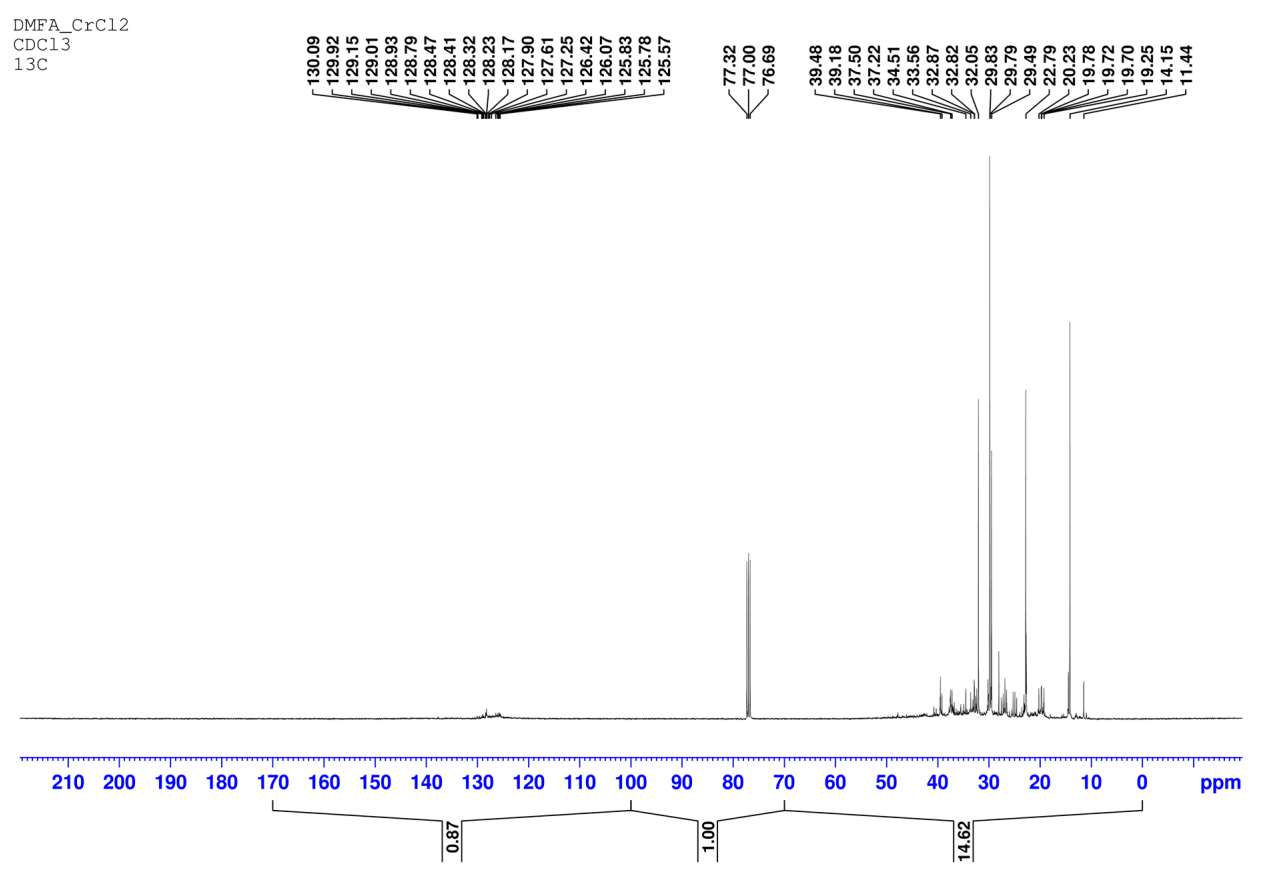

Figure $3 .{ }^{13} \mathrm{C}$ NMR spectra of the desulfurized diesel fraction $200-350{ }^{\circ} \mathrm{C}$.

In the ${ }^{13} \mathrm{C}$ NMR spectrum a signal of carbon atoms corresponding to saturated structures in the range $0-70 \mathrm{ppm}$ with an integrated intensity $\mathrm{I}_{\mathrm{sat}}=19.51$ and a signal of carbon atoms corresponding to aromatic structures with an integrated intensity $I_{a}=1.81$ are observed. The aromaticity factor is

$$
\mathrm{F}_{\mathrm{a}}=\mathrm{I}_{\mathrm{a}} /\left(\mathrm{I}_{\mathrm{a}}+\mathrm{I}_{\mathrm{sat}}\right)=0.08489 .
$$

In the PMR spectrum the signals of protons of aromatic nuclei (region 6.5-8.5 ppm), protons of $\mathrm{CH}, \mathrm{CH}_{2}$, and $\mathrm{CH}_{3}$ groups located in the $\alpha$-positions of aromatic nuclei (1.8-4 ppm) are observed. Protons of hydrocarbon radicals more distant from the aromatic nucleus are partially superimposed on signals of protons of aliphatic hydrocarbons (0.8-1.8 ppm).

In the ${ }^{13} \mathrm{C}$ NMR spectrum the signal of carbon atoms corresponding to saturated structures in the range $0-70 \mathrm{ppm}$ with an integrated intensity $\mathrm{I}_{\mathrm{sat}}=14.62$ and a signal of carbon atoms corresponding to aromatic structures with an integrated intensity $I_{a}=0.87$ are observed. The aromaticity factor is

$$
\mathrm{F}_{\mathrm{a}}=\mathrm{I}_{\mathrm{a}} /\left(\mathrm{I}_{\mathrm{a}}+\mathrm{I}_{\mathrm{sat}}\right)=0.05616 .
$$

In the PMR spectrum the signals of protons of aromatic nuclei in the range 6.5-8.5 ppm and protons of $\mathrm{CH}, \mathrm{CH}_{2}, \mathrm{CH}_{3}$ groups located in the $\alpha$-positions of aromatic nuclei (1.8-4 ppm) are observed. Protons of hydrocarbon radicals more distant from the aromatic nucleus are partially superimposed on signals of protons of aliphatic hydrocarbons $(0.8-1.8 \mathrm{ppm})$. All these data indicate a decrease in the content of aromatic hydrocarbons in the diesel fraction approximately by $33 \%$.

\subsection{Extraction of SCC by DMF-CdCl $, \mathrm{CoCl}_{2}, \mathrm{CuCl}_{2}, \mathrm{MnCl}_{2}, \mathrm{CrCl}_{3}, \mathrm{Co}(\mathrm{TFA})_{2}, \mathrm{Mn}(\mathrm{TFA})_{2}, \mathrm{Cu}(\mathrm{TFA})_{2}$ Extraction Systems}

Table 3 shows the results of extraction of the sulfur-containing fraction boiling in the temperature range of $200-350^{\circ} \mathrm{C}$ with solutions of chlorides and metal trifluoroacetates in DMSO. 
Table 3. Extraction of sulfur compounds from the fraction boiling in the temperature range of 200-350 ${ }^{\circ} \mathrm{C}$ with saturated solutions of chlorides and metal trifluoroacetates in DMSO. The total sulfur content $\left(S_{\text {tot }}\right)$ in the initial sample is $0.2 \%$. $S_{\text {tot }}$ content in the initial sample after treatment with DMSO is $0.18 \%$. The extraction time is $30 \mathrm{~min}$. The temperature is $25^{\circ} \mathrm{C}$.

\begin{tabular}{cccc}
\hline Metal Salts & $\begin{array}{c}\text { Concentration of the Metal } \\
\text { Salt in DMSO, mol/dm }\end{array}$ & $\mathbf{S}_{\text {tot, } \%}$ & $\begin{array}{c}\text { Degree of Extraction of } \\
\text { Sulfur Compounds, \% }\end{array}$ \\
\hline $\mathrm{CdCl}_{2}$ & 0.12 & 0.10 & 33.3 \\
$\mathrm{CoCl}_{2}$ & 0.50 & 0.06 & 66.6 \\
$\mathrm{CuCl}_{2}$ & 1.76 & 0.06 & 66.6 \\
$\mathrm{MnCl}_{2}$ & 2.50 & 0.04 & 76.6 \\
$\mathrm{CrCl}_{3}$ & 2.75 & 0.03 & 78.8 \\
$\mathrm{Co}(\mathrm{TFA})$ & 0.11 & 0.05 & 70.0 \\
$\mathrm{Mn}(\mathrm{TFA})_{2}$ & 0.11 & 0.04 & 78.3 \\
$\mathrm{Cu}(\mathrm{TFA})_{2}$ & 0.11 & 0.06 & 68.8 \\
\hline
\end{tabular}

It is difficult to evaluate the interaction of metal salts with DMSO, since it is both a soft and hard base. DMSO is an ambidentate ligand, i.e., it contains a lone electron pair both with an oxygen atom and with a sulfur atom, but only one atom of either oxygen or sulfur can participate in the coordination to the metal ion. When reacting with hard acids $\left(\mathrm{MnCl}_{2} \mathrm{CrCl}_{2}\right.$, and $\left.\mathrm{Mn}(\mathrm{TFA})_{2}\right), \mathrm{DMSO}$ should exhibit the properties of a hard base and be coordinated to the metal ion via an oxygen atom. Conversely, with mild acids, such as cadmium sulfide, DMSO should be coordinated to the cadmium ion via a sulfur atom. According to the data presented in Table 3, the best yields of sulfur are given by systems containing hard Lewis acids.

\section{Conclusions}

The process of removal of sulfur compounds from diesel fuels by solutions of chlorides $\left(\mathrm{CdCl}_{2}\right.$, $\mathrm{CuCl}_{2}, \mathrm{CoCL}_{2}, \mathrm{MnCl}_{2}, \mathrm{CrCl}_{3}$ ) and metal trifluoroacetates ( $\mathrm{Co}, \mathrm{Mn}$, and $\left.\mathrm{Cu}\right)$ in dimethylformamide and dimethyl sulfoxide has been studied. It was shown that extraction of sulfur-containing compounds from a diesel fuel with residual sulfur content $0.18 \%$ proceeds under mild conditions, at a temperature of $25^{\circ} \mathrm{C}$ and atmospheric pressure for $30 \mathrm{~min}$. The residual SCC content after 2-step extraction is less than $90 \%$.

The interaction of organic solvents with metal salts and sulfur-containing compounds of the diesel fraction was considered within the framework of HSAB concept. It was shown that the most complete extraction of SCC was carried out by the DMF-Mn(TFA) $)_{2}, \mathrm{MnCl}_{2}$, and $\mathrm{CrCl}_{3}$ systems, which is due to the hard base-hard acid interaction.

The PMR method has shown by the example of DMF and cobalt chloride, that the addition of a metal salt to the coordinating polar solvent results in the coordination of the metal cation through the oxygen atom of the DMF carbonyl group, which leads to a redistribution of the electron density in the solvent molecule and enhancement of properties of the acceptor center localized on the nitrogen atom.

Thus, the work shows that extraction systems based on coordinating organic solvents and metal salts may be well suited for the removal of sulfur compounds from diesel fuels.

Author Contributions: N.S.K., T.S.S., O.S.A., E.I.M. and V.I.S. conceived of and designed the experiments; T.S.S., E.I.M. performed the experiments, O.S.A. and V.I.S. analyzed the data; N.S.K. wrote the paper.

Funding: This research was funded by Ministry of Education and Science of the Russian Federation grant No. RFMEFI57817X0225.

Acknowledgments: The work is performed with financial support of the Ministry of Education and Science of the Russian Federation. Grant agreement No. RFMEFI57817X0225.

Conflicts of Interest: The authors declare no conflict of interest. 


\section{References}

1. Lyapina, N.K. Chemistry and Physicochemistry of Sulfur Compounds of Oil Distillates. M. Nauka. 1984, 120.

2. Speight, J.G. The Desulfurization of Heavy Oils and Residua; Marcel Dekker Inc.: New York, NY, USA, 2000; Volume 459.

3. Mel'nikova, L.A.; Lyapina, N.K.; Parfenova, M.A. Sulphides and thiophenes of sulphur petroleum distillates. Pet. Chem. U.S.S.R. 1981, 24, 50-56. [CrossRef]

4. Kaminsky, E.F.; Khavkin, V.A. Deep Oil Conversion: Technological and Environmental Aspects; M. Publisher Tekhnika; JLC ‘TUMA GROUP'; EBSCO Industries: Birmingham, AL, USA, 2001; Volume 384.

5. Zolotukhin, V.A. A New Technology for the Processing of Heavy Oil and Residues of Oil Refineries. Chem. Oil Gas Eng. 2004, 10, 8-11.

6. Wan Mokhtar, W.; Abu Bakar, W.; Rusmidah, A. Deep Desulfurization of Model Diesel with N,N-dimethylformamide: Optimization by Box-Behnken Design. J. Taiwan Inst. Chem. Eng. 2014, 35, 314-319. [CrossRef]

7. Safarov, B.Z.; Shamsieva, M.B.; Normurodov, B.R. Extraction of Oil Sulfides and Sulfoxides from High-Sulfur Diesel Distillates by the Extraction Method. Young Sci. 2014, 9, 200-204.

8. Kolbin, V.A.; Dezortsev, S.V.; Telyashev, E.G.; Kreimer, M.L.; Akhmetov, A.F. Extractive Upgrading of Diesel Fractions with N-methylpirrolidone. Bashk. Chem. J. 2016, 23, 3-6.

9. Kianpour, E.; Azizian, S. Polyethylene Glycol as a Green Solvent for Effective Extractive Desulfurization of Liquid Fuel at Ambient Conditions. Fuel 2014, 137, 36-40. [CrossRef]

10. Saifidinov, B.M.; Nigmatullin, V.R.; Sharipov, A.K.; Nigmatullin, I.R. Removal of sulfur compounds from light fractions of South Uzbek oils. Chem. Technol. Fuels Oils 2012, 48, 356-359. [CrossRef]

11. Savinova, I.A.; Min, R.S.; Plyusnin, A.N. Extraction of Sulfur-Aromatic Compounds of Oil Components by a Combination of Methods of Complex Formation and Extraction. Sib. Chem. J. 1992, 1, 8-11.

12. Min, R.S.; Savinova, I.A. Isolation of sulphur compounds of crude oil with solutions of metal chlorides in electron-donor organic solvents. Pet. Chem. 1997, 37, 537-545.

13. Karyakin, Y.V.; Angelov, I.I. Pure Chemical Substances. M. Chem. 1974, 407.

14. Glazunova, T.Y.; Boltalin, A.I.; Troyanov, S.I. Novel chromium trinuclear trifluoroacetate complexes $\mathrm{Cr}_{3}\left(\mu_{3}-\mathrm{O}\right)\left(\mathrm{CF}_{3} \mathrm{COO}\right)_{6}\left(\mathrm{CH}_{3} \mathrm{COOH}\right)_{2}\left(\mathrm{CF}_{3} \mathrm{COO}\right)$ and $\mathrm{Cr}_{3}\left(\mu_{3}-\mathrm{O}\right)\left(\mathrm{CF}_{3} \mathrm{COO}\right)_{6}\left(\mathrm{CH}_{3} \mathrm{COOH}\right)_{2}(\mathrm{THF})$ : Synthesis and crystal structure. Russ. J. Coord. Chem. 2005, 31, 247-252. [CrossRef]

15. Pearson, R.G. Hard and Soft Acids and Bases. Am. Oil Chem. Soc. 1963, 85, 3533-3539. [CrossRef] 